\title{
Paraneoplastic Syndromes in Dogs
}

\author{
Almir Pereira de Souza* and Olívia Maria Moreira Borges \\ Veterinary Medicine Postgraduate Program, Brazil \\ *Corresponding author: Almir Pereira de Souza, Veterinary Medicine Postgraduate Program, Patos, PB, Brazil

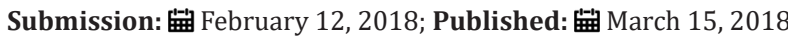

\begin{abstract}
Para Neoplastic Syndromes (PNS) are defined as a heterogeneous group of clinical and/or laboratory abnormalities that precede or occur simultaneously with a neoplasm or its metastases and can occur in both small animals and humans with comparatively similar symptoms. It is important to mention that PNS have already been described in the systems gastrointestinal, endocrine, circulatory/hematological, neurological, bone and nonspecific. Thus, recognizing and describing a PNS early on, whether common or not, is of great value in veterinary, given its importance in assisting the diagnosis and treatment of neoplastic processes.
\end{abstract}

Keywords: Neoplasm; Metastases; Diagnosis; Canine

Abbreviations: PNS: Paraneoplastic Syndromes

\section{Introduction}

Table 1: Occurrence of a few paraneoplastic syndromes in small animals and in humans.

\begin{tabular}{|c|c|c|c|}
\hline Paraneoplastic Syndromes & Dog & Cat & Human \\
\hline Myasthenia Gravis & Yes & Yes & Yes \\
\hline Peripheral Neuropathy & Rare & Rare & Yes \\
\hline Cerebellar degeneration & Yes & Yes & Yes \\
\hline Hypoglycemia & Yes & Yes & Yes \\
\hline Hypercalcemia & Yes & Yes & Yes \\
\hline Anemia & Yes & Yes & Yes \\
\hline Thrombocytopenia & Yes & Yes & Yes \\
\hline Feline Paraneoplastic Alopecia & No & Yes & No \\
\hline Nodular Dermatofibrosis & Yes & Yes & Yes \\
\hline Acantose Nigricans & No & No & Yes \\
\hline Sweet Syndrome & No & No & Yes \\
\hline Cachexia & Yes & Yes & Yes \\
\hline Hypertrophic Osteopathy & Yes & No & No \\
\hline
\end{tabular}

Para Neoplastic Syndromes (PNS) are defined as a heterogeneous group of clinical and/or laboratory abnormalities that precede or occur simultaneously with a neoplasm or its metastases. PNS can occur in both small animals and humans with comparatively similar symptoms (Table 1), being considered indirect side effects of cancer and may arise from humoral, hormonal, tumor or immune response to neoplasms, and characterized by ectopy of sites distant from the neoplastic site. Although important and described as important predictors or markers of possible regression or progression of oncologic disease, studies reporting the prevalence of these alterations in veterinary are not available currently, being largely restricted to human medicine, where approximately $75 \%$ of cancer patients reportedly display paraneoplastic changes during the evolution of the neoplasia [1] .

Therefore, PNS early recognition and clinical applicability are of great value in the clinical routine, since they may be the first sign of malignancy, and timely diagnosis can drastically influence patient prognosis and treatment [2]. Thus, the objective of this review is to describe the paraneoplastic syndromes in dogs, especially the less common PNS, since the knowledge and ability to recognize them early on can improve significantly the prognosis of cancer patients.

\section{Paraneoplastic syndromes in dogs}

PNSs are complex diseases/symptoms that may occur individually or in different body systems. To this end, it is important to mention that PNSs have already been described in the following systems: gastrointestinal (cachexia and gastrointestinal ulceration), endocrine (hypercalcemia, hypoglycemia and hyperestrogenism), circulatory/hematological (hypergammaglobulinemia, anemia, erythrocytosis, neutrophilic leukocytosis, leukopenia, disseminated intravascular coagulation (alopecia and nodular dermatofibrosis), neurological (myasthenia gravis and cerebellar degeneration), bone (peripheral osteopathy) and nonspecific (fever). In view of this clinical-hematological diversity, the formation mechanisms, clinical presentation and neoplastic origin of the less described and possibly frequent, but equally important paraneoplastic syndromes in the clinical routine of small animals are highlighted in the following paragraphs. 


\section{Hypertension and medullary hypoplasia forming mechanism}

Excess estrogen interferes with the differentiation of hematopoietic stem cells, altering the iron use by erythrocyte precursors, and inhibiting production of erythrocyte stimulating factor in the circulation. Estrogenic marrow intoxication induces granulocytopoietic increase and reduction of megakaryocytes and erythroid elements, leading initially to neutrophilia with left-sided deviation, thrombocytopenia and anemia, which may lead to a plasia or pancytopenia.

a. Neoplastic origin: Tumor of granulosa and supportive cells (sertolioma).

b. Clinical signs: Hematological, myelosuppression induced by hyperestrogenism, which is characterized by pancytopenia, may be observed. Clinically, the feminization syndrome shows slowly progressive alopecia, symmetrical, bilateral, and usually originating in the neck, lumbar region, perineum and genital region. Other findings include macular melanoma in the inguinal, perineal, and genital regions, and linear preputial dermatosis [3,4].

\section{Nodular dermatofibrosis forming mechanism}

Little known, but is believed to be of hereditary autosomal dominant origin and full penetrance.

a. Neoplastic origin: renal cystadenocarcinoma and uterine leiomyomas.

b. Clinical signs: Non-specific, but correlated to stages of uremia. The skin nodular lesions can be located in the trunk, head and distal portion of the limbs, especially between the digits and the cushions, when it leads to lameness [5].

\section{Myasthenia gravis forming mechanism}

The acquired form is triggered by the existence of antibodies against acetylcholine receptors in the neuromuscular junction, whereas the congenital form is the result of the hereditary deficiency of acetylcholine in the postsynaptic membranes of musculature.

a. Neoplastic origin: thymoma, osteosarcoma, lymphoma, biliary carcinoma and primary lung neoplasms. b. Clinical signs: intermittent muscle weakness, exercise intolerance, dysphagia, megaesophagus, and respiratory paralysis [6].

\section{Cerebellar degeneration: forming mechanism}

Ectopic expression of neuronal antigens by the tumor tissue, triggering immune response against it, and cross-reaction against the antigens present in the nervous system, resulting in neurological manifestations.

a. Neoplastic origin: Lymphoma, mammary, pulmonary and ovarian carcinoma.

b. Clinical signs: ataxia and imbalances [7].

Thus, recognizing and describing a PNS early on, whether common or not, is of great value in veterinary, given its importance in assisting the diagnosis and treatment of neoplastic processes. Unusual paraneoplastic abnormalities such as hyperestrogenism, medullary hypoplasia, nodular dermatofibrosis, myasthenia gravis, and cerebellar degeneration should be remembered and considered in the evaluation of dogs with neoplasias since it could lead to a more adequate clinical management.

\section{References}

1. Morrison WB (2002) Paraneoplastic syndromes and the tumors that cause them. In: Morrison WB (Ed.), Cancer in dogs and cats. ( $\left.2^{\text {nd }} e d n\right)$, Williams e Wilkins, Baltimore, USA, pp. 731-743.

2. Bergman PJ (2013) Paraneoplastic syndromes In: Withrow and MacEwen's (Eds.), Small animal clinical oncology. ( $5^{\text {th }}$ edn), St. Saunders Elsevier, Louis, pp. 83-97.

3. Bosschere HDE, Deprest C (2010) Estrogen-induced pancytopenia due to a Sertoli cell tumor in a cryptorchid Beauceron. Vlaams Diergeneeskundig Tijdschrift 79.

4. Scott DW, Miller WH, Griffin CE (2001) In: Muller \& Kirk's (Ed.), Small animal dermatology. $\left(6^{\text {th }}\right.$ edn), Saunders, Philadelphia, USA.

5. Langohr IM, Irigoyen LF, Salles, MWS, Kommers GD, Barros CSL (2002) Cistadeno carcinoma renal e dermatofibrose nodular em cães pastor alemão: 4 casos. Cienc. Rural 32(4): 621-626.

6. Morrison WB (2007) Systemic Syndromes associated with cancer The North American Veterinary Conference, Orlando, Florida, USA.

7. Bardy FB, Cagy M, Filho FP, lamarca JE, Rabinovitz M, et al. (2000) Degeneração cerebelar subaguda paraneoplásica - Relato de caso. Arq neuropsiquiatr 58(3A): 764-768.
Creative Commons Attribution 4.0

International License

For possible submissions Click Here

\section{Submit Article}

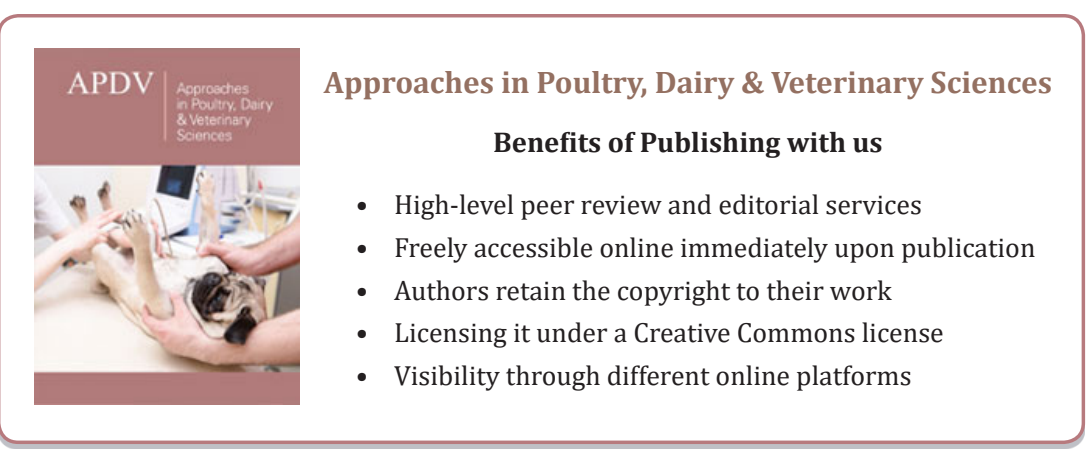

